\title{
Long-term stability of climate and global glaciations throughout the evolution of the Earth
}

\author{
Eiichi Tajika \\ Department of Earth and Planetary Science, Graduate School of Science, University of Tokyo, Japan \\ (Received November 7, 2005; Revised December 6, 2006; Accepted December 8, 2006; Online published May 7, 2007)
}

\begin{abstract}
Earth's climate is considered to be stable on the order of $>10^{6}$ years, owing to a negative feedback mechanism in a carbon cycle system. However, any decrease in net input flux of $\mathrm{CO}_{2}$ to the atmosphere-ocean system (i.e., volcanic-metamorphic $\mathrm{CO}_{2}$ flux minus excess organic carbon burial flux) lowers the surface temperature and would eventually initiate global glaciation. The $F_{D}-F_{B}^{O}$ diagram $\left(F_{D}\right.$ : the total $\mathrm{CO}_{2}$ degassing flux, $F_{B}^{O}$ : the organic carbon burial flux) is proposed as a measure of the susceptibility of the Earth to global glaciations. By using this diagram with the carbon fluxes estimated from a carbon cycle model during the Phanerozoic, the net input flux of $\mathrm{CO}_{2}$ is found to have been very close to the critical condition for a global glaciation at the Late Paleozoic. During the Proterozoic, a carbon isotope mass balance model with this diagram shows that global glaciations occurred probably due to a decrease in the $\mathrm{CO}_{2}$ degassing in addition to an increase in the organic carbon burial. Because the Sun becomes brighter as it evolves, the critical level of atmospheric $\mathrm{CO}_{2}$ pressure to cause global glaciation will be lower than the critical $\mathrm{CO}_{2}$ pressure for photosynthesis of $\mathrm{C} 4$ plants within 500 million years. At this point, the net input flux of $\mathrm{CO}_{2}$ will be too large to cause global glaciations. Continuous volcanic-metamorphic activities (i.e., plate tectonics) may be one of the necessary conditions for the Earth and Earth-like planets in extrasolar planetary systems to keep liquid water and life over the timescales of planetary evolution.
\end{abstract}

Key words: Carbon cycle, global glaciation, snowball Earth, astrobiology.

\section{Introduction}

The climate of the Earth has been warm $\left(>0^{\circ} \mathrm{C}\right)$ during most of its geological history (Fig. 1), as suggested from evidence for the continued presence of liquid water and life (Walker, 1982; Kasting, 1989). Such a long-term stability of the Earth's climate is explained by a negative feedback mechanism within the carbon cycle system (Walker et al., 1981; Kasting, 1989; Kasting and Toon, 1989; Tajika and Matsui, 1990, 1992, 1993; Broecker and Sanyal, 1998). Paleomagnetic studies, however, revealed the evidence of low-latitude ice sheets during the Proterozoic (Evans et al., 1997; Evans, 2000), which could be interpreted to be a result of global glaciations (Kirschvink, 1992, 2002; Hoffman et al., 1998; Hoffman and Schrag, 2002).

Global glaciation may be caused by a decrease of the atmospheric $\mathrm{CO}_{2}$ partial pressure $\left(p \mathrm{CO}_{2}\right)$ to a certain critical level (e.g., Caldeira and Kasting, 1992; Ikeda and Tajika, 1999), because the greenhouse effect of $\mathrm{CO}_{2}$ plays a key role in keeping the Earth's climate warm (e.g., Walker et al., 1981). The critical $\mathrm{CO}_{2}$ level has been studied by using general circulation models (GCMs) combined with ice sheet and/or sea ice models under the conditions of reduced solar flux and paleocontinental distribution during the Neoproterozoic (e.g., Jenkins and Smith, 1999; Hyde et al., 2000; Donnadieu et al., 2004a).

Copyright (c) The Society of Geomagnetism and Earth, Planetary and Space Sciences (SGEPSS); The Seismological Society of Japan; The Volcanological Society of Japan; The Geodetic Society of Japan; The Japanese Society for Planetary Sciences; TERRAPUB
There are, however, several possibilities which would decrease $p \mathrm{CO}_{2}$ in the carbon cycle system. For example, an increase in the organic carbon burial may have decreased $p \mathrm{CO}_{2}$, causing the global glaciations during the Neoproterozoic (Kaufman et al., 1997; Hoffman et al., 1998). Tajika (2004) showed that the reduction of volcanicmetamorphic activities would have been required to cause the global glaciations, in addition to the increased rate of organic carbon burial. In contrast, Donnadieu et al. (2004b) argued that the decrease of $p \mathrm{CO}_{2}$ could have been caused by an increase in silicate weathering rate, owing to an increase in runoff and emplacement of flood basalt through the break-up of the supercontinent Rodinia.

It is, therefore, important to clarify the condition of the carbon cycle system to cause global glaciations. Because the susceptibility of the Earth to global glaciations may change with time, it is useful to estimate the generalized condition of the carbon cycle system to cause global glaciations over the Earth's evolution (from the past to the future). Such an attempt has never been made to date, but will be important for understanding the susceptibility of the Earth to global glaciations and also the evolution of Earth-like planets which will be found in extrasolar planetary systems in the near future.

In this study, the general condition of the carbon flux required for the initiation of global glaciation is estimated by analyzing a simple climate model with a carbon cycle system. We propose the $F_{D}-F_{B}^{O}$ diagram $\left(F_{D}\right.$ : the total $\mathrm{CO}_{2}$ degassing flux, $F_{B}^{O}$ : the organic carbon burial flux) 


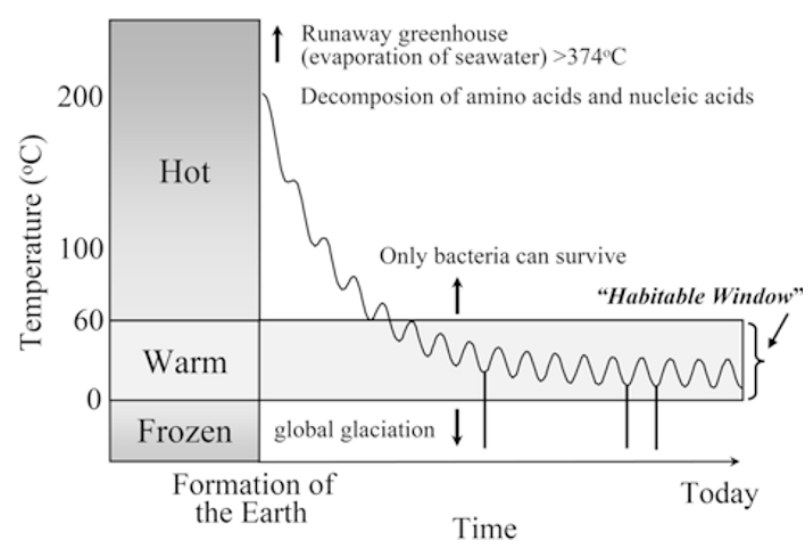

Fig. 1. Climate evolution of the Earth. The climate of the Earth may have been warm $\left(>0^{\circ} \mathrm{C}\right)$ and suitable for life during the most of the geological history, although global glaciations have occurred at least three times during the Proterozoic (e.g., Kirschvink, 1992, 2002; Hoffman et al., 1998; Hoffman and Schrag, 2002). The early Earth could have been "hot" $\left(>60^{\circ} \mathrm{C}\right.$ ) if the land masses were small (e.g., Tajika and Matsui, $1990,1992,1993)$ and there were no microbial activity on the land surface (e.g., Schwartzman and Volk, 1989).

as a measure of the susceptibility of the Earth to global glaciations. By using this diagram and carbon cycle models during the Phanerozoic and the Neoproterozoic, variations of carbon fluxes during these two geological ages are discussed in the context of global glaciations. Finally, the susceptibility of the Earth to global glaciations in its evolution is discussed.

\section{Long-term Climate Stability and Global Glaciations}

A mechanism to stabilize the Earth's climate on geological time scales (more than $10^{6}$ years) resides in the carbon cycle system (Walker et al., 1981; Berner et al., 1983). The dominant process for the atmospheric $\mathrm{CO}_{2}$ consumption is the weathering of silicate minerals, followed by the precipitation of carbonates in the ocean. Silicate weathering rate $\left(F_{W}^{S}\right)$ depends strongly on temperature $(T)$ and $p \mathrm{CO}_{2}$ (e.g., Walker et al., 1981; Schwartzman and Volk, 1989), that is,

$$
F_{W}^{S} \propto f_{E} \cdot f_{B}\left(T, p \mathrm{CO}_{2}\right)
$$

where $f_{E}$ and $f_{B}$ represent the soil biological activity (=1 at present) and the weathering feedback function, respectively. Mass balance of carbon in the atmosphere-ocean system is represented simply by

$$
\frac{d M_{A O}}{d t}=F_{i n}-F_{W}^{S}\left(T, p \mathrm{CO}_{2}\right)
$$

where $M_{A O}$ is the amount of $\mathrm{CO}_{2}$ in the atmosphere-ocean system, and $F_{\text {in }}$ is the net $\mathrm{CO}_{2}$ input flux via volcanismmetamorphism (e.g., Walker et al., 1981).

Figure 2 shows the schematic behaviors of the solution of Eq. (2). We assume here that the average flux of $\mathrm{CO}_{2}$ degassing via volcanism-metamorphism does not change on the order of $10^{6}$ years. If the surface temperature increases for any reason (a certain perturbation or a short-term event), then $\mathrm{CO}_{2}$ would be removed from the atmosphere-ocean system by increased rate of silicate weathering, followed

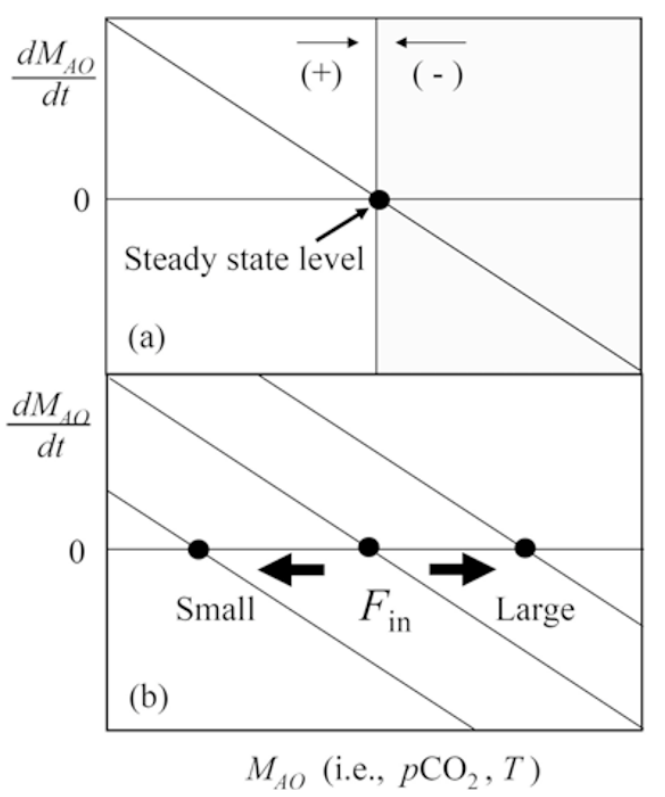

Fig. 2. Concept of the negative feedback mechanism for surface temperature of the Earth due to carbon cycle (Walker et al., 1981). (a) Amount of $\mathrm{CO}_{2}$ in the atmosphere-ocean system. $M_{A O}$ (thus, $p \mathrm{CO}_{2}$ or $T$ ), changes so that $M_{A O}$ may be in a steady state. When $M_{A O}$ is larger than the steady-state level, a warmer climate would remove extra amount of $\mathrm{CO}_{2}$ owing to silicate weathering followed by carbonate precipitation in the ocean. When $M_{A O}$ is smaller, $\mathrm{CO}_{2}$ would accumulate in the atmosphere-ocean system owing to $\mathrm{CO}_{2}$ degassing via volcanism-metamorphism. (b) The steady-state level of $M_{A O}$ should change according to the net $\mathrm{CO}_{2}$ input flux $F_{i n}$ into the atmosphere-ocean system. When $F_{\text {in }}$ is large, the steady-state level becomes large (climate becomes warm). When $F_{i n}$ is small, the steady-state level becomes small (climate becomes cool).

by carbonate precipitation in the ocean. Similarly, if the surface temperature decreases, $\mathrm{CO}_{2}$ would accumulate in the atmosphere-ocean system through the decreased rate of silicate weathering. In either case, deviation from the steady state would be damped, and the system tends to maintain a steady state (Fig. 2(a)). Because of this negative feedback mechanism, the Earth's climate may have been suitable for life throughout the geological history despite variations of climate factors, such as solar luminosity (Walker et al., 1981; Kasting and Toon, 1989; Tajika and Matsui, 1990).

It is, however, noted that several boundary conditions to control $F_{i n}$ and the efficiency of $F_{W}^{S}$ should have changed with time. Such factors include volcanic-metamorphic activities, organic carbon budget (imbalance of weathering and burial of organic carbon), soil biological activity (Walker et al., 1981; Berner et al., 1983; Lasaga et al., 1985; Schwartzman and Volk, 1989; Tajika and Matsui, 1992, 1993; Tajika, 1998, 1999; Berner, 1994).

The boundary conditions change the steady-state levels of $T$ and $p \mathrm{CO}_{2}$ (Fig. 2(b)). When $F_{i n}$ is large, steady-state levels become large (climate becomes warm), and climate becomes cool for small $F_{i n}$. If $F_{i n}$ were below a certain critical level, the Earth would be globally ice-covered. Therefore, global glaciations are caused even if the system has a mechanism to stabilize the climate.

Then, in order to understand the physical aspects of global glaciation, we summarize behaviors of the climate system obtained from one-dimensional energy balance cli- 


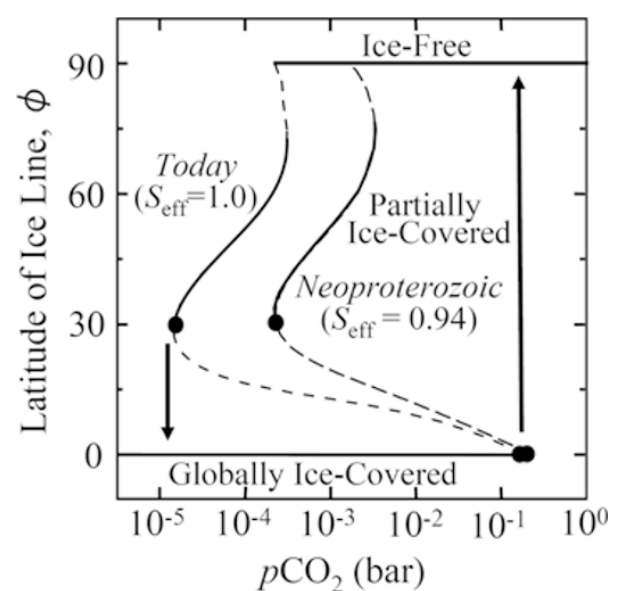

Fig. 3. The steady-state solutions of 1-D EBM for two cases of the normalized solar flux $S_{\text {eff }}$ ( 1 for today and 0.94 for Neoproterozoic). Solid lines, dashed lines, and solid circles represent stable solutions, unstable solutions, and critical conditions (where stable solution disappears), respectively. Arrows represent climate jump due to climate instability for the case of $S_{\text {eff }}=1$.

mate models (1-D EBMs). The 1-D EBM considers energy balance among the solar incident flux, the latitudinal heat transport, and the outgoing infrared radiation at each latitude, and ice cap with high surface albedo is assumed to extend from poles to lower latitudes (e.g., North et al., 1981). When we assume the outgoing radiation as functions of $p \mathrm{CO}_{2}$ and $T$ (Caldeira and Kasting, 1992; Ikeda and Tajika, 1999), the surface temperature at each latitude and the latitude of the ice line (ice cap edge) against $p \mathrm{CO}_{2}$ can be obtained (Figs. 3 and 4).

Figure 3 shows typical results for steady-state solutions of latitude of ice line against $p \mathrm{CO}_{2}$ for two cases of the normalized solar flux (1.0 for today and 0.94 for the Neoproterozoic). It is well known that there are three kinds of stable climate states: the ice-free branch, the partially icecovered branch, and the globally ice-covered branch (North et al., 1981), as represented by solid curves in Fig. 3.

As $p \mathrm{CO}_{2}$ decreases from the partially ice-covered branch, the ice cap extends to lower latitudes. When $p \mathrm{CO}_{2}$ reaches a critical value and the ice line reaches $\approx 30^{\circ}$, the Earth falls into the globally ice-covered branch, owing to the climate instability (North et al., 1981). Figure 4 shows changes in the surface temperature distribution (a) from the partially ice-covered to the globally ice-covered branch and (b) from the globally ice-covered to the ice-free branch, obtained from the same model. The surface temperature decreases drastically through the climate instability (Fig. 4(a)), because the planetary albedo becomes very high.

The global glaciation would not continue because $\mathrm{CO}_{2}$ is released via volcanism-metamorphism and accumulates on the order of 0.1 bar in the atmosphere in several million years on the globally glaciated Earth (Kirschvink, 1992; Hoffman et al., 1998). Then, the globally ice-covered branch disappears, and the climate shifts to the ice-free branch (Figs. 3 and 4(b)).

In these respects, we conclude that the concept of the long-term climate stability and the occurrence of global

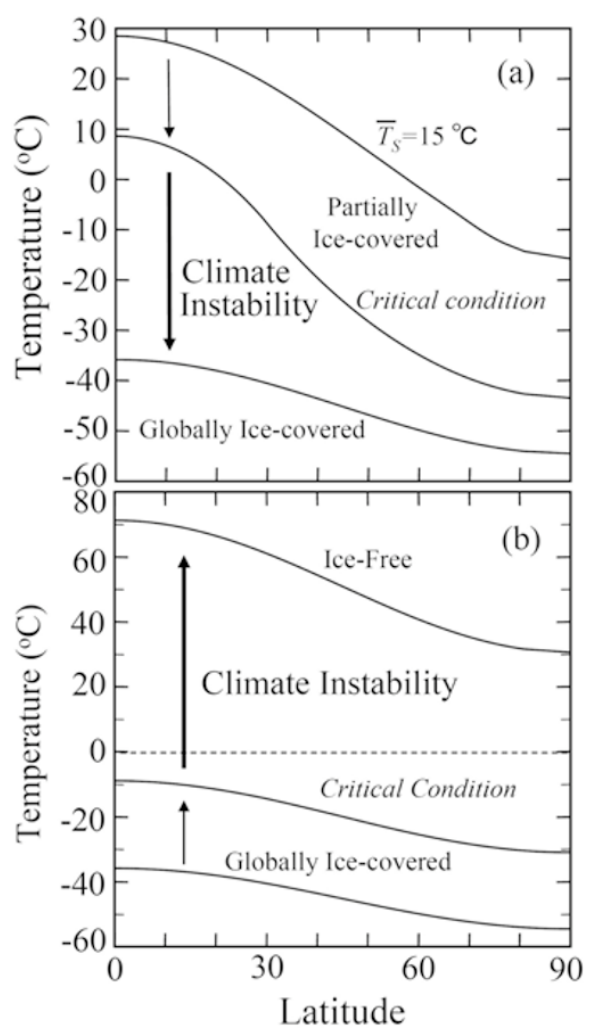

Fig. 4. Changes in the latitudinal temperature distribution through the snowball Earth event. (a) Change in the temperature distribution from a warm climate (the globally-averaged surface temperature is $15^{\circ} \mathrm{C}$ ) to the critical condition, and to the globally ice-covered state. (b) Change in the temperature distribution from the globally ice-covered state to the critical condition, and to the ice-free state.

glaciations do not contradict with each other.

\section{Critical Condition of $\mathrm{CO}_{2}$ Flux}

We now estimate the critical condition of the $\mathrm{CO}_{2}$ flux in the carbon cycle system to cause the climate instability described in the previous chapter.

When we consider more detailed mass balance of carbon in the atmosphere-ocean system than Eq. (2), we should describe the net $\mathrm{CO}_{2}$ input flux to the atmosphere-ocean system, $F_{i n}$, as follows (see Tajika (2003)):

$$
F_{\text {in }}=F_{D}+F_{W}^{O}-F_{B}^{O}
$$

where $F_{D}$ is the total degassing rate of $\mathrm{CO}_{2}$ via volcanismmetamorphism, $F_{W}^{O}$ is the weathering rate of organic carbon, and $F_{B}^{O}$ is the burial rate of organic carbon. Note that we regarded $F_{i n} \approx F_{D}$ (i.e., $F_{W}^{O} \approx F_{B}^{O}$ ) in the previous chapter.

For the time scale of more than $10^{5}$ years, we can assume that the atmosphere-ocean system is in a steady state. Then, Eq. (2) is rewritten by

$$
F_{\text {in }}=F_{W}^{S}\left(T, p \mathrm{CO}_{2}\right)
$$

The critical value of $F_{i n}$ to cause the climate instability may be estimated from Eq. (4) with the $p \mathrm{CO}_{2}$ level and the latitudinal temperature distribution at the critical condition (Fig. 4(a)) by integrating the weathering rate from the equator to the ice line as a function of temperature at 


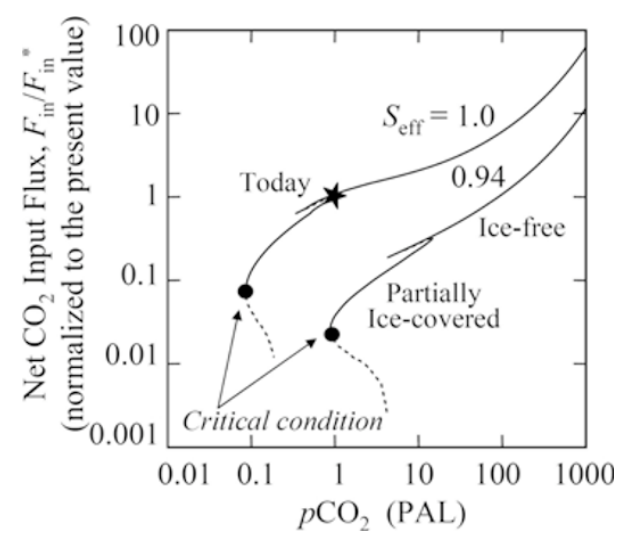

Fig. 5. The net $\mathrm{CO}_{2}$ input flux (normalized to the present rate) and the atmospheric $\mathrm{CO}_{2}$ level (in PAL $=$ present atmospheric level) for the normalized solar flux $S_{\text {eff }}=1.0$ (today) and 0.94 (Neoproterozoic). The critical condition is represented by a solid circle for each case.

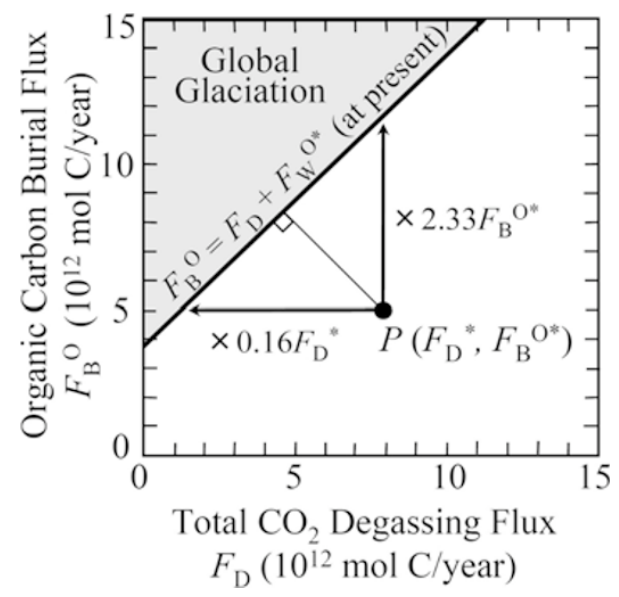

Fig. 6. The $F_{D}-F_{B}^{O}$ diagram as a measure of the susceptibility of the Earth to global glaciations. The thick solid line represents the critical condition for the carbon fluxes to cause a climate instability to the globally ice-covered state. The solid circle $P$ represents the flux condition today. Superscript $*$ represents the present-day value.

each latitude. Figure 5 shows the relation between $F_{\text {in }}$ and the steady-state level of $p \mathrm{CO}_{2}$. The critical value of $F_{\text {in }}$ is estimated to be $\approx 5.0 \times 10^{11} \mathrm{~mol} /$ year at present and $\approx 1.5 \times 10^{11} \mathrm{~mol} /$ year at 750 million years ago $(\mathrm{Ma})$, which are less than $1 / 10$ and $1 / 40$ of the present-day flux $\left(\approx 6.65 \times 10^{12} \mathrm{~mol} /\right.$ year; Berner, 1994), respectively. The critical $F_{i n}$ should be such low values because $F_{W}^{S}$ becomes very low under the climate at the critical condition.

We therefore approximate $F_{i n}\left(=F_{W}^{S}\right) \approx 0$ at the critical condition. This approximation provides the lower limit of the critical condition regardless of the choice of models and model parameters, and does not depend on the precise value of the critical $p \mathrm{CO}_{2}$ because the approximation $F_{W}^{S} \approx$ 0 corresponds to the assumption $T<0^{\circ} \mathrm{C}$ even at the equator. As a result, from Eq. (3), the critical condition is represented by

$$
F_{B}^{O}=F_{D}+F_{W}^{O}
$$

This relation can be expressed by a line in a $F_{D}-F_{B}^{O}$ space, as shown in Fig. 6 (hereafter we call this "the $F_{D}-F_{B}^{O}$ diagram").

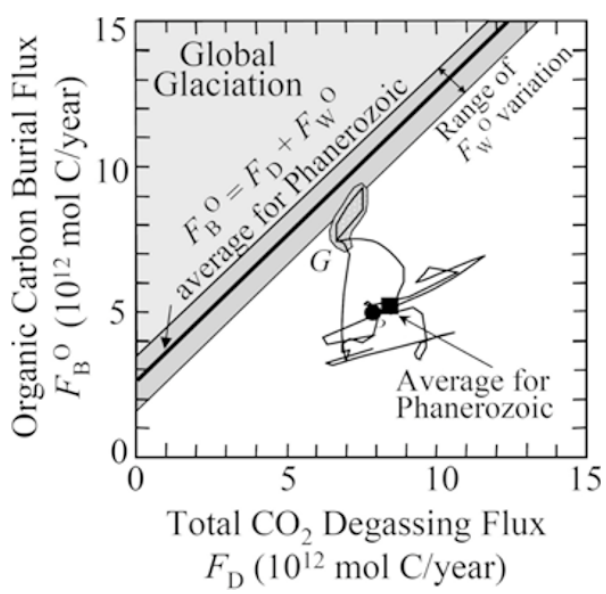

Fig. 7. Trajectory of temporal variation of $\mathrm{CO}_{2}$ fluxes during the Phanerozoic estimated from a carbon cycle model (GEOCARB II: Berner, 1994). Hatched region $G$ represents the conditions for the Late Paleozoic glaciation at around $300 \mathrm{Ma}$. Lines, solid circle, and solid square represent the critical condition, the flux condition today, and the average flux condition obtained from averaging the calculated results throughout the Phanerozoic, respectively. Note that the average condition during the Phanerozoic is very close to the condition today.

The susceptibility of the Earth to global glaciations is measured by a distance between this line and the $\mathrm{CO}_{2}$ flux condition. For example, the present $\mathrm{CO}_{2}$ flux condition $\left(F_{D}^{*}\right.$ and $F_{B}^{O *}$ where $*$ represents the present-day value) is represented by the solid circle $P$ in Fig. 6. Then, in order to cause global glaciation, $F_{D}$ should become $<1.25 \times$ $10^{12} \mathrm{~mol} /$ year $\left(=F_{D}^{*}-F_{i n}^{*}\right.$, or $<0.16$-fold the present-day value) when $F_{B}^{O}$ and $F_{W}^{O}$ remain constant. Similarly, $F_{B}^{O}$ should become $>11.65 \times 10^{12} \mathrm{~mol} /$ year $\left(=F_{B}^{O *}+F_{i n}^{*}\right.$, or $>2.33$-fold the present-day value) when $F_{D}$ and $F_{W}^{O}$ remain constant. Note that the minimum distance between the line and $P$ does not correspond to $F_{i n}^{*}$, but to $F_{i n}^{*} / \sqrt{2}$ in this diagram. This means that simultaneous variations of $F_{D}$ and $F_{B}^{O}$ affect the climate change effectively.

In the following, we evaluate the $\mathrm{CO}_{2}$ flux condition in the Phanerozoic and the Neoproterozoic, respectively, and discuss the susceptibility of the Earth to global glaciations in these ages.

\subsection{Phanerozoic}

In order to evaluate the condition for $\mathrm{CO}_{2}$ fluxes during the Phanerozoic, we adopt a carbon cycle model called GEOCARB (Berner, 1994). This model considers carbon mass balance and carbon isotope mass balance by parameterizing each geochemical process as functions of various factors, such as the seafloor spreading rate. Carbon isotopic composition of marine carbonate is used as boundary conditions. We recalculate the carbon cycle during the Phanerozoic with the GEOCARB model to evaluate the $\mathrm{CO}_{2}$ flux condition during this time interval by plotting the results on the $F_{D}-F_{B}^{O}$ diagram.

Figure 7 shows the resulting trajectory of carbon fluxes $\left(F_{D}\right.$ and $\left.F_{B}^{O}\right)$ during the Phanerozoic. The weathering rate of organic carbon $\left(F_{W}^{O}\right)$ also varies, but within a range shown by a hatched region in Fig. 7. This figure clearly shows that the critical condition was never achieved during the Phanerozoic. 
It should be noted, however, that the $\mathrm{CO}_{2}$ fluxes (hatched region $G$ in Fig. 7) might have been very close to the critical condition during the Late Paleozoic glaciation at about 300 Ma when $F_{W}^{O}$ was very close to the Phanerozoic average (represented by thick line in Fig. 7).

In fact, based on studies of paleosols, $p \mathrm{CO}_{2}$ is estimated to have been very low (as low as 150-200 ppm) at about $300 \mathrm{Ma}$ (Mora et al., 1996). Furthermore, based on studies of the distribution of ice-rafted debris, ice sheets could have advanced to $35^{\circ}$ paleo-latitude in the Westphalian (in the Late Carboniferous) and Sakamarian (in the Early Permian) (Frakes and Francis, 1988; Frakes et al., 1992). This value is close to the critical condition expected from EBMs (Fig. 3), supporting the idea that the Late Paleozoic glaciation may have been close to the critical condition for a global glaciation.

The large-scale glaciation of this period is considered to have been caused by a large drop in $p \mathrm{CO}_{2}$ as a result of the rise of vascular plants which accelerated the rate of $\mathrm{CO}_{2}$ uptake by weathering (Berner, 1993, 1997). These plants also provided a new source of bacterially resistant organic matter, such as lignin, removing $\mathrm{CO}_{2}$ by the massive burial of sedimentary organic carbon during this period (Berner, 1993, 1997). For some unknown reason, however, the critical condition was not achieved at that time, and the Late Paleozoic glaciation did not develop into global glaciation.

\subsection{Neoproterozoic}

It has been argued that global glaciations occurred during the Proterozoic (Kirschvink, 1992; Hoffman et al., 1998). If the Earth really experienced global glaciations during this period, how was the critical condition achieved?

One possible cause for global glaciations during the Proterozoic could be the significant reduction of the net $\mathrm{CO}_{2}$ input flux, owing to an increase in the organic carbon burial and/or a decrease in the $\mathrm{CO}_{2}$ degassing rate. According to studies of carbon isotopic composition of seawater during the Neoproterozoic, the average value of $\delta^{13} \mathrm{C}$ was much higher than that for the Phanerozoic, and the $\delta^{13} \mathrm{C}$ value increased up to $1 \%$ o before the glaciations (Kaufman et al., 1977; Hayes et al., 1999). This is interpreted as a result of the high rate of organic carbon burial, resulting in a large reduction of the net input flux of $\mathrm{CO}_{2}$ and causing the global glaciations (Kaufman et al., 1997; Hoffman et al., 1998).

The above possibility was evaluated by Tajika (2004), using a carbon isotope mass balance model combined with the 1-D EBM and with the record of carbon isotopic composition of marine carbonates during the Neoproterozoic. Tajika (2004) found that an increase in the organic carbon burial alone cannot cause global glaciations. Here we recalculate the carbon cycle with the same model and evaluate the resulting carbon flux conditions in the $F_{D}-F_{B}^{O}$ diagram (Fig. 8). Because we do not know the temporal variations of $F_{D}$ and $F_{W}^{O}$ during the Neoproterozoic, these parameters are assumed to be constant. We use several constant values for these parameters to evaluate the conditions for global glaciations.

The flux of the organic carbon burial increased at the timing of positive excursions of $\delta^{13} \mathrm{C}$ during the Neoproterozoic. The increase in the organic carbon burial alone cannot, however, cause global glaciations when the present values

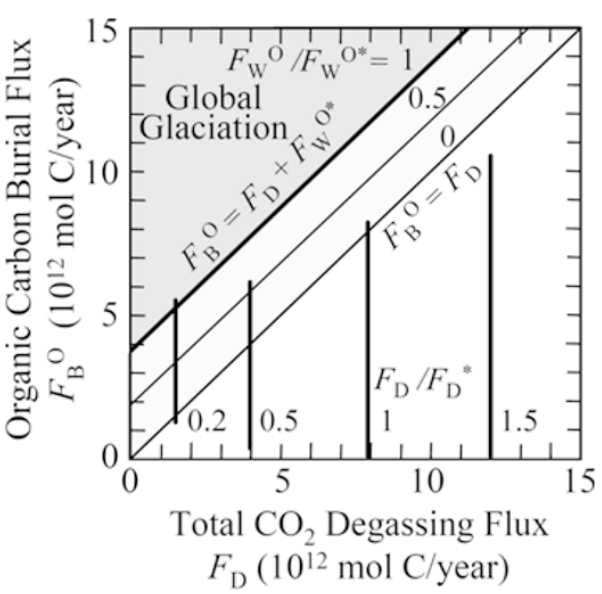

Fig. 8. Temporal variations of the organic carbon burial flux, $F_{B}^{O}$, through the Neoproterozoic estimated from a carbon isotope mass balance model with carbon isotope data (Hayes et al., 1999). Weathering rate of organic carbon, $F_{W}^{O}$, and the total $\mathrm{CO}_{2}$ degassing flux, $F_{D}$, are given as constant values in the model.

of $F_{D}$ and $F_{W}^{O}$ are assumed in the model (Fig. 8): the average surface temperature varies within the range of a very warm condition in this case (Fig. 9). This is because there were no vascular land plants before the Silurian-hence the soil biological activity, $f_{E}$, was low $(<1)$, and so the climate should have been warm in order to balance the silicate weathering rate with a large net $\mathrm{CO}_{2}$ input rate (see Eqs. (1) and (4)).

When the $\mathrm{CO}_{2}$ degassing rate is assumed to be low $(<1 / 4)$, however, the condition for global glaciation can be achieved at an extensive burial rate of organic carbon (Figs. 8 and 9). Such a decrease in the $\mathrm{CO}_{2}$ degassing rate could have been resulted from a reduction of volcanicmetamorphic activities or a decrease in the average carbonate content in the subducting deep-sea sediments, owing to the changes in distribution (shallow/deep) of carbonate precipitation in the ocean. Lower weathering rate of organic carbon due to a lower level of oxygen content in the atmosphere during the Neoproterozoic than those of today (e.g., Canfield, 2005) might have also provided a favorable condition for the initiation of global glaciations (Fig. 8).

A recent study on the $\mathrm{U}-\mathrm{Pb}$ age of detrital zircons from river sands in three major rivers in North and South America reveals that a time interval between $800-600 \mathrm{Ma}$ is characterized by one of the lowest levels of continental growth (that is, subduction volcanism) during the geological history (Fig. 10; Rino et al., 2004). This suggests that the period of the Neoproterozoic global glaciations seems to coincide with the period of the lowest volcanic activity, at least, at subduction zones. Because a significant portion of $\mathrm{CO}_{2}$ degassing occurs via subduction volcanism today (Sano and Williams, 1996; Marty and Tolstikhn, 1998), the lowest activity of subduction volcanism might have resulted in the reduction of global $\mathrm{CO}_{2}$ input.

There was another period of the very low population of zircon grains between 2500-2300 Ma (Fig. 10; Rino et al., 2004). In this period, a series of glaciations occurred, and there is additional evidence for low-latitude ice-sheet (i.e., evidence for global glaciation) obtained from the Transvaal 


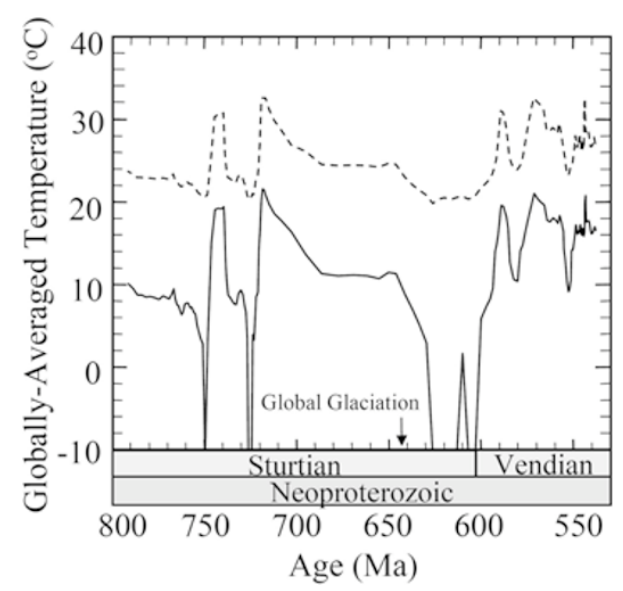

Fig. 9. Temporal variations of globally-averaged surface temperature during the Neoproterozoic for the case of the present $\mathrm{CO}_{2}$ degassing rate (dashed curve) and the case of the low $\mathrm{CO}_{2}$ degassing rate $(1 / 4$ of the present rate; solid curve).

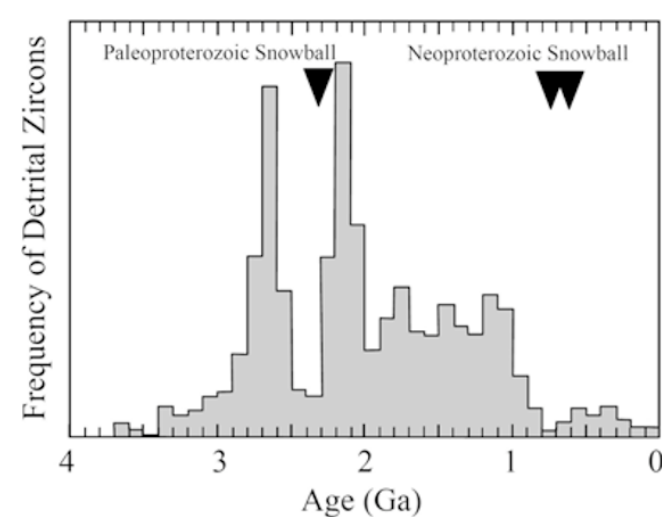

Fig. 10. Age population of zircons in river sands of the North and South American continents (modified from Rino et al., 2004).

Supergroup on the Kaapvaal craton in South Africa (Evans et al., 1997; Kirschvink et al., 2000). Therefore, the Paleoproterozoic global glaciation could have been also explained by a low $\mathrm{CO}_{2}$ degassing rate due to a reduction of volcanic-metamorphic activities.

\section{Susceptibility to Global Glaciations throughout the Earth's Evolution}

According to studies of thermal evolution of the Earth, the potential temperature of the mantle has decreased through the Earth's history (e.g., Christensen, 1985). Then, an efficiency of magma generation, volcanism, and activity of plate tectonics (hence the $\mathrm{CO}_{2}$ degassing via volcanismmetamorphism) may have decreased with time, suggesting that it might be more likely to cause global glaciations with time.

On the other hand, because the luminosity of the Sun increases as the Sun evolves (Gough, 1981), the critical level of $\mathrm{CO}_{2}$ for the climate instability also changes with time (Fig. 5). Figure 11 shows temporal variations of the critical level of $\mathrm{CO}_{2}$ and the atmospheric $\mathrm{CO}_{2}$ level required for maintaining the average surface temperature at $15^{\circ} \mathrm{C}$ in the past and the future.

As the atmospheric $\mathrm{CO}_{2}$ level decreases owing to the in-

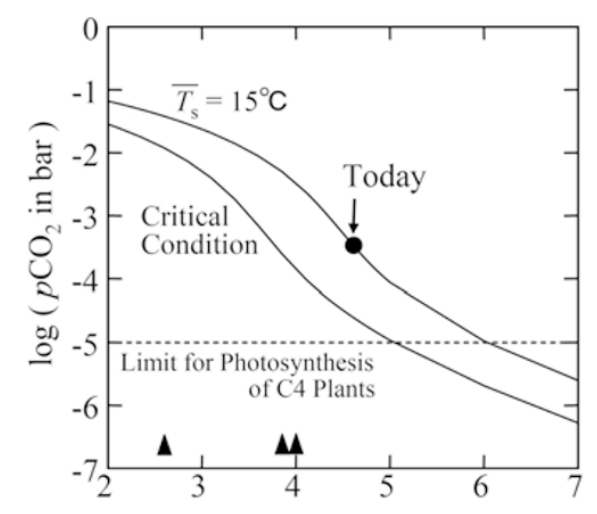

Гime after the Formation of the Earth ( $10^{9}$ years)

Fig. 11. Temporal variations of the atmospheric $\mathrm{CO}_{2}$ level for the critical condition and for a warm climate (globally-averaged surface temperature $=15^{\circ} \mathrm{C}$ ) from 2.6 billion years before to 2.4 billion years after the present. Solid triangles represent the global glaciations during the Proterozoic. The horizontal line represents the critical $\mathrm{CO}_{2}$ level for photosynthesis of $\mathrm{C} 4$ plants. Note that the climate model adopted here may not be accurate for low $p \mathrm{CO}_{2}$ levels predicted for the future because radiative parameters were approximated with an error under $5 \mathrm{~W} / \mathrm{m}^{2}$ for $10^{-4}$ bar $<p \mathrm{CO}_{2}<2$ bar (Caldeira and Kasting, 1992). Nevertheless, this result may represent a qualitative trend of the critical $\mathrm{CO}_{2}$ level variation with time.

crease in the solar flux (e.g., Walker et al., 1981), it will be under the limit for photosynthesis of C3 plants, and finally fall under the limit for photosynthesis of $\mathrm{C} 4$ plants $(<10$ ppm). But before that, the critical $\mathrm{CO}_{2}$ level (not the atmospheric $\mathrm{CO}_{2}$ level) fall under the limit for photosynthesis of $\mathrm{C} 4$ plants after 500 million years from now (Fig. 11). Then, if a reduction of volcanic-metamorphic activities occurs and the atmospheric $\mathrm{CO}_{2}$ level decreases to this limit, the net $\mathrm{CO}_{2}$ input flux should become large because $\mathrm{CO}_{2}$ cannot be fixed as organic carbon efficiently. In such a situation, even if $\mathrm{CO}_{2}$ degassing rate becomes zero, global glaciation does not occur any more.

Although the susceptibility of the Earth to global glaciations in the evolution should depend on the competition of mantle cooling and solar luminosity enhancement, it will take a much longer time for the mantle activity to decrease drastically (e.g., the average mantle temperature would have decreased $150-250^{\circ}$ for the last 3 billion years; Christensen, 1985). Therefore, before the mantle becomes cool enough to cause permanent global glaciation, the influence of the solar luminosity becomes important. As a consequence, the Earth will not be globally glaciated after 500 million years from now.

The Earth's climate could have been suitable for life during the most of the geological history because a certain level of volcanic-metamorphic activities due to spreading and subduction of oceanic plates has maintained sufficient net $\mathrm{CO}_{2}$ input flux. As described earlier, even if the Earth was globally glaciated, the Earth could have escaped from such a regime, owing to an accumulation of $\mathrm{CO}_{2}$ via volcanismmetamorphism.

In these respects, plate tectonics may be one of the necessary conditions for the Earth and Earth-like planets in extrasolar planetary systems to keep liquid water and life over the timescales of the planetary evolution. 


\section{Summary}

Any decrease in the net input flux of $\mathrm{CO}_{2}$ to the atmosphere-ocean system lowers the surface temperature and would eventually initiate global glaciation. The $F_{D^{-}}$ $F_{B}^{O}$ diagram is proposed for measuring the susceptibility of the Earth to global glaciations. By analyzing results from a carbon cycle model during the Phanerozoic, the net input flux of $\mathrm{CO}_{2}$ may have been very close to the critical condition at the Late Paleozoic glaciation. During the Proterozoic, global glaciations occurred probably by reduction of the $\mathrm{CO}_{2}$ degassing in addition to an increase in the organic carbon burial. It will be more unlikely for the Earth to be globally glaciated after 500 million years from now, because the Sun becomes brighter as it evolves. Continuous volcanic-metamorphic activities (i.e., plate tectonics) may be one of the necessary conditions for Earth-like planets in extrasolar planetary systems to keep liquid water and life on their surface over the timescales of the planetary evolution.

Acknowledgments. I would like to thank N. Shikazono and an anonymous reviewer for their reviews and helpful comments. This research was partially supported by the grants-in-aid for Scientific Research (No. 14403004 and No. 18340128) of Japan Society for the Promotion of Science.

\section{References}

Berner, R. A., Paleozoic atmospheric $\mathrm{CO}_{2}$ : importance of Solar Radiation and plant evolution, Science, 261, 68-70, 1993.

Berner, R. A., GEOCARB II: A revised model of atmospheric $\mathrm{CO}_{2}$ over Phanerozoic time, Am. J. Sci., 294, 56-91, 1994.

Berner, R. A., The rise of plants and their effect on weathering and atmospheric $\mathrm{CO}_{2}$, Science, 276, 544-546, 1997.

Berner, R. A., A. C. Lasaga, and R. M. Garrels, The carbonate-silicate geochemical cycle and its effect on atmospheric carbon dioxide over the past 100 million years, Am. J. Sci., 283, 641-683, 1983.

Broecker, W. S. and A. Sanyal, Does atmospheric $\mathrm{CO}_{2}$ police the rate of chemical weathering?, Global Biogeochem. Cycles, 12, 403-408, 1998.

Caldeira, K. and J. F. Kasting, Susceptibility of the early Earth to irreversible glaciation caused by carbon dioxide clouds, Nature, 359, 226228, 1992.

Canfield, D. E., The early history of atmospheric oxygen, Annu Rev. Earth Planet. Sci., 33, 1-36, 2005.

Christensen, U. R., Thermal evolution models for the Earth, J. Geophys. Res., 90, 2995-3007, 1985.

Donnadieu, Y., Y. Godderis, G. Ramstein, A. Nedelec, and J. Meert, A 'snowball Earth' climate triggered by continental break-up through changes in runoff, Nature, 428, 303-306, 2004a.

Donnadieu, Y., G. Ramstein, F. Fluteau, D. Roche, and A. Ganopolski, The impact of atmospheric and oceanic heat transports on the sea-ice-albedo instability during the Neoproterozoic, Climate Dynamics, 22, 293-306, 2004b.

Evans, D. A., Stratigraphic, geochronological, and paleomagnetic constraints upon the Neoproterozoic climatic paradox, Am. J. Sci., 300, 374-433, 2000.

Evans, D. A., N. J. Beukes, and J. L. Kirschvink, Low-latitude glaciation in the Paleoproterozoic era, Nature, 386, 262-266, 1997.

Frakes, L. A. and J. E. Francis, A guide to Phanerozoic cold polar climates from high-latitude ice-rafting in the Cretaceous, Nature, 333, 547-549, 1988.

Frakes, L. A., J. E. Francis, and J. I. Syktus, Climate Modes of the Phanerozoic, 274 pp., Cambridge Univ. Press, Cambridge, 1992.

Gough, D. O., Solar interior structure and luminosity variations, Sol. Phys., 74, 21-34, 1981.

Hayes, J. M., H. Strauss, and A. J. Kaufman, The abundance of $\delta^{13} \mathrm{C}$ in marine organic matter and isotopic fractionation in the global biogeochemical cycle of carbon during the past $800 \mathrm{Ma}$, Chem. Geol., 161, 103-125, 1999.

Hoffman, P. F. and D. P. Schrag, The snowball Earth hypothesis: testing the limits of global change, Tera Nova, 14, 129-155, 2002.

Hoffman, P. F., A. J. Kaufman, G. P. Halverson, and D. P. Schrag, A Neoproterozoic Snowball Earth, Science, 281, 1342-1346, 1998.

Hyde, W. T., T. J. Crowley, S. K. Baum, and W. R. Peltier, Neoproterozoic 'snowball Earth' simulations with a coupled climate/ice-sheet model, Nature, 405, 425-429, 2000.

Ikeda, T. and E. Tajika, A study of the energy balance climate model with $\mathrm{CO}_{2}$-dependent outgoing radiation: implication for the glaciation during the Cenozoic, Geophys. Res. Lett., 26, 349-352, 1999.

Jenkins, G. S. and S. R. Smith, GCM simulations of snowball Earth conditions during the late Proterozoic, Geophys. Res. Lett., 26, 2263-2266, 1999.

Kasting, J. F., Theoretical constraints on oxygen and carbon dioxide concentrations in the Precambrian atmosphere, Precambrian Res., 34, 205229, 1989.

Kasting, J. F. and O. B. Toon, Climate evolution on the terrestrial planets, in Origin and Evolution of Planetary and Satellite Atmospheres, edited by M. S. Matthews, J. B. Pollack, and S. K. Atreya, 881 pp., Univ. of Arizona, Tucson, 423-449, 1989.

Kaufman, A. T., A. H. Knoll, and G. M. Narbonne, Isotopes, ice ages, and terminal Proterozoic earth history, Nat. Acad. Sci.Proc., 94, 6600-6605, 1997.

Kirschvink, J. L., Late Proterozoic low-latitude global glaciation: the Snowball Earth, in The Proterozoic Biosphere, edited by J. W. Schopf and C. Klein, 1348 pp., Cambridge Univ. Press, 51-52, 1992.

Kirschvink, J. L., When all of the oceans were frozen, La Recherche, $\mathbf{3 5 5}$, 26-30, 2002 (in French).

Kirschvink, J. L., E. J. Gaidos, L. E. Bertani, N. J. Beukes, J. Gutzmer, L. N. Maepa, and R. E. Steinberger, Paleoproterozoic snowball Earth: Extreme climatic and geochemical global change and its biological consequences, Proc. Natl. Sci. Acad., 97, 1400-1405, 2000.

Lasaga, A. C., R. A. Berner, and R. M. Garrels, An improved geochemical model of atmospheric $\mathrm{CO}_{2}$ fluctuations over past 100 million years, in The Carbon Cycle and Atmospheric $\mathrm{CO}_{2}$ : Natural Variations Archean to Present, edited by E. T. Sundquist and W. S. Broecker, 635 pp., American Geophysical Union, Washington, DC, 397-411, 1985.

Marty, B. and I. N. Tolstikhn, $\mathrm{CO}_{2}$ fluxes from mid-ocean ridges, arcs and plumes, Chem. Geol., 145, 233-248, 1998.

Mora, C. I., S. G. Driese, and L. Colarusso, Middle to late Paleozoic atmospheric $\mathrm{CO}_{2}$ levels from soil carbonate and organic matter, Science, 271, 1105-1107, 1996.

North, G. R., R. F. Cahalan, and J. A. Coakley, Energy balance climate models, Rev. Geophys. Space Phys., 19, 91-121, 1981.

Rino, S., T. Komiya, B. F. Windley, I. Katayama, A. Motoki, and T. Hirata, Major episodic increases of continental crustal growth determined from zircon ages of river sands; implications for mantle overturns in the Early Precambrian, Phys. Earth Planet. Int., 146, 369-394, 2004.

Sano, Y. and S. N. Williams, Fluxes of mantle and subducted carbon along convergent plate boundaries, Geophys. Res. Lett., 23, 2749-2752, 1996. Schwartzman, D. W. and T. Volk, Biotic enhancement of weathering and the habitability of Earth, Nature, 340, 457-460, 1989.

Tajika, E., Climate change during the last 150 million years: Reconstruction from a carbon cycle model, Earth Planet. Sci. Lett., 160, 695-707, 1998.

Tajika, E., Carbon cycle and climate change during the Cretaceous inferred from a carbon biogeochemical cycle model, The Island Arc, 8, 293-303, 1999.

Tajika, E., Faint young Sun and the carbon cycle: Implication for the Proterozoic global glaciations, Earth Planet. Sci. Lett., 214, 443-453, 2003.

Tajika, E., Analysis of carbon cycle system during the Neoproterozoic: Implication for snowball Earth events, in Multidisciplinary Studies Exploring Extreme Proterozoic Environment Conditions, edited by G. Jenkins, C. Mckay, and L. Sohl, 220 pp., AGU Geophysical Monograph, American Geophysical Union, 146, 45-54, 2004.

Tajika, E. and T. Matsui, The evolution of the terrestrial environment, in Origin of the Earth, edited by H. E. Newsom and J. H. Jones, 378 pp., Oxford Univ. Press, New York, N.Y., pp. 347-370, 1990.

Tajika, E. and T. Matsui, Evolution of terrestrial proto- $\mathrm{CO}_{2}$-atmosphere coupled with thermal history of the Earth, Earth Planet. Sci. Lett., 113, 251-266, 1992.

Tajika, E. and T. Matsui, Degassing history and carbon cycle: From an impact-induced steam atmosphere to the present atmosphere, Lithos, 30, 267-280, 1993.

Walker, J. C. G., Climatic factors on the Archean Earth, Palaeogeogr. Palaeoclimat. Palaeoecol., 40, 1-11, 1982.

Walker, J. C. G., P. B. Hays, and J. F. Kasting, A negative feedback mechanism for the long-term stabilization of Earth's surface temperature, $J$. Geophys. Res., 86, 9776-9782, 1981.

E. Tajika (e-mail: tajika@eps.s.u-tokyo.ac.jp) 